\title{
Erratum: Breakdown study based on direct in situ observation of inner surfaces of an rf accelerating cavity during a high-gradient test [Phys. Rev. Accel. Beams 19, 102001 (2016)]
}

Tetsuo Abe, Tatsuya Kageyama, Hiroshi Sakai, Yasunao Takeuchi, and Kazuo Yoshino

(Received 16 August 2018; published 24 August 2018)

DOI: 10.1103/PhysRevAccelBeams.21.089901

We have found an error in our paper that the vertical scale of Fig. 7 is an order of magnitude smaller than that of the correct figure. This error has no effect on the results or conclusions of our paper. The correct figure is shown below.

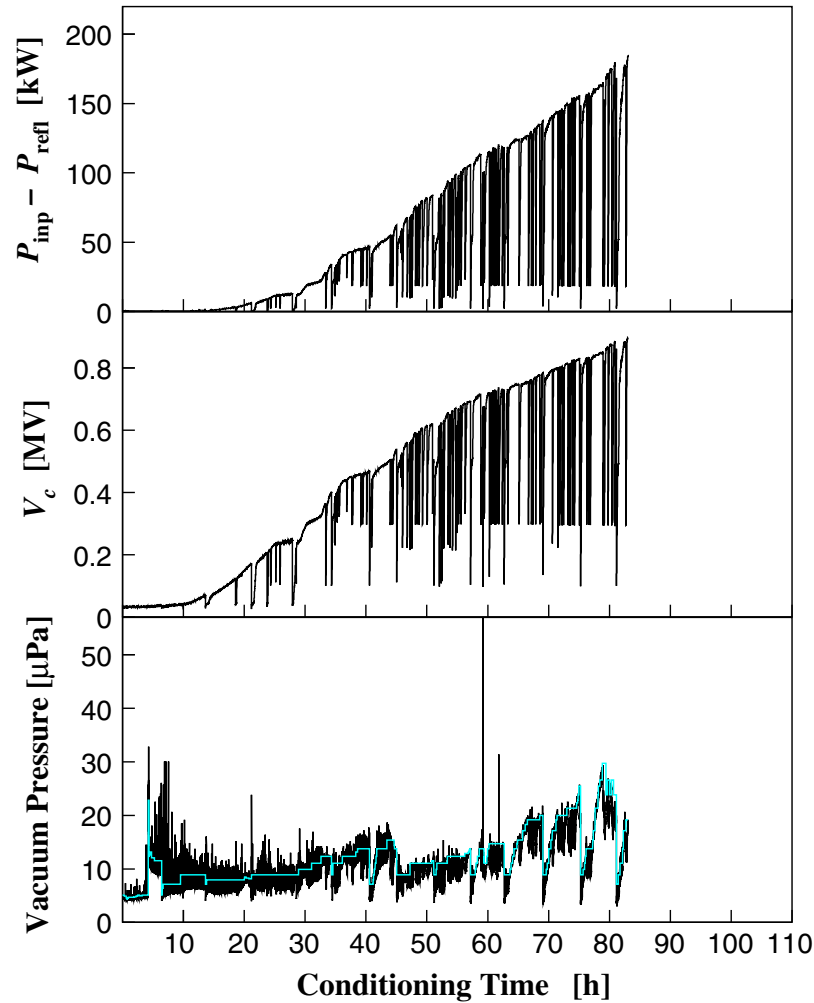

(a) DR cavity No. 1

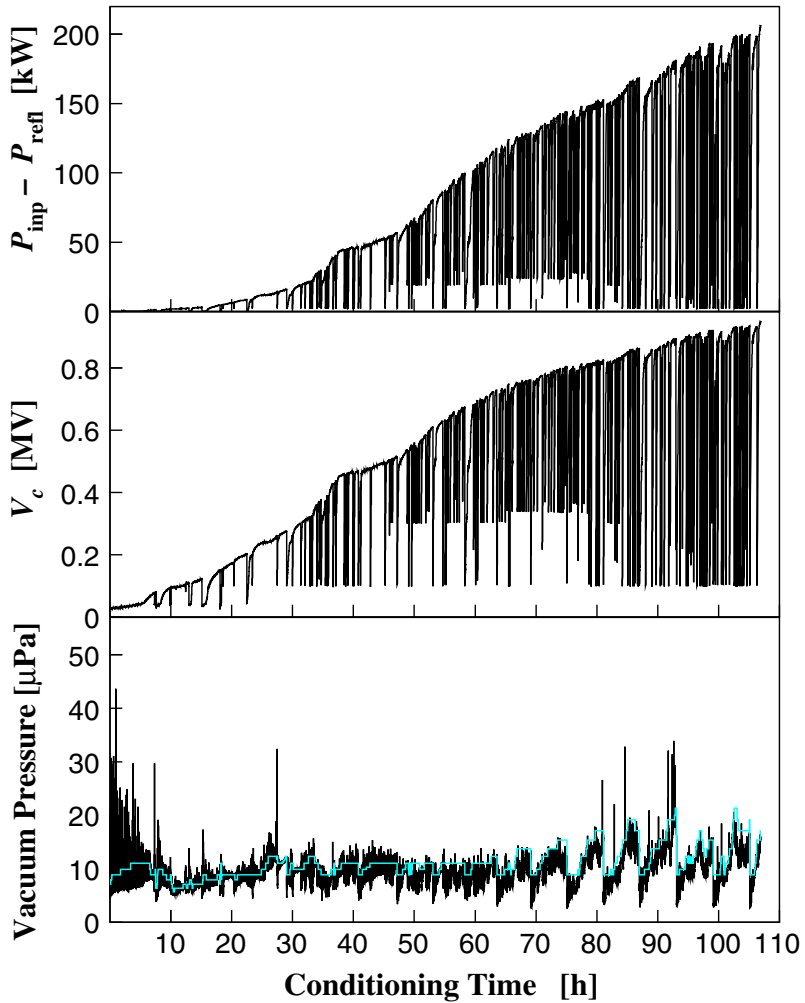

(b) DR cavity No. 2

FIG. 7. Conditioning histories until $V_{c}$ reached (a) $0.90 \mathrm{MV}$ for DR cavity No. 1 and (b) $0.95 \mathrm{MV}$ for DR cavity No. 2 with data points recorded every $10 \mathrm{~s}$. Data with no input rf power, data while the input rf power was kept constant, and data used to tune the control system or klystron are excluded here. The light blue lines indicate the reference vacuum pressure specified in the automatic conditioning by computer control. If the vacuum pressure is higher than the reference pressure, the rf power is stepped down until the vacuum pressure becomes lower than the reference pressure, and then the power is gradually stepped up as long as the vacuum pressure is lower than the reference pressure. The step-up slope is proportional to the difference between the reference and vacuum pressures.

Published by the American Physical Society under the terms of the Creative Commons Attribution 3.0 License. Further distribution of this work must maintain attribution to the author(s) and the published articles title, journal citation, and DOI. 